\title{
HUBUNGAN KUALITAS PELAYANAN DENGAN KEPUASAN PASIEN RAWAT JALAN DI PUSKESMAS BELAWAN Yulina ${ }^{1}$, Rapael Ginting ${ }^{2}$
}

${ }^{1}$ Fakultas Kesehatan Masyarakat, Universitas Prima Indonesia, Medan

2Dosen Fakultas Kesehatan Masyarakat, Universitas Prima Indonesia, Medan

E-mail: yulinawang96@gmail.com

DOI : https://doi.org/10.35451/jkg.v2i1.204

\begin{abstract}
Quality of service can be interpreted as conformity of professional standards with the utilization of resources effectively and efficiently, so that the needs of patients can be achieved optimal degree. Based on the Legatum Prosperity Index (2017) data which states Indonesia's global Health Index is ranked at 101 from 149 countries, this is because there are still many remote areas that are still difficult to access health care. Satisfaction to the quality of service as much as $51.0 \%$ of respondents who rate dissatisfied, such as the process of receiving the patient is served slowly, health officers do not timely come, and lack of hospitality of health officers in response to complaints Patients. The design of this research is an analytical survey with the Cross Sectional approach. The number of research populations is 98 outpatients. The sampling technique used is Purposive Sampling. Data retrieval using questionnaire measuring instrument. Analysis of data conducted in the analysis of Univariate and bivariate (test Chi-Square). The results of this study showed that the reliability with the $P$ value is $0.042<0.05$, the responsiveness with a value of $P$ is $0.041<0.05$, empathy with the value $P$ is $0.015<0.05$, and the guarantee with the value $P$ is $0.042<0.05$. Conclusions are reliability, responsiveness, empathy and assurance of having a relationship with patient satisfaction. It is hoped that Belawan health center to improve the service of reliability, responsiveness, assurance and empathy in Belawan Health Center.
\end{abstract}

\section{Keywords: quality of service, patient satisfaction, belawan health center}

\section{PENDAhuluan}

Kualitas pelayanan adalah kesesuaian standar profesi dengan pemanfaatan sumber daya secara efektif dan efisien, sehingga kebutuhan pasien dapat tercapai dengan derajat optimal (Tribowo, 2013).

Berdasarkan data Legatum Prosperity Index (2016) dari 149 negara, Luxemburg berada di peringkat ke- 1 dan Singapura di peringkat ke- 2 yang memiliki sistem kesehatan terbaik di dunia. Hal ini dikarenakan negara maju mempunyai layanan kesehatan yang baik serta kesehatan mereka dijamin oleh pemerintah .

Berdasarkan data Legatum

Prosperity Index (2017) yang menyatakan indeks kesehatan global Indonesia berada di peringkat ke- 101 dari 149 negara. Hal ini masih banyaknya wilayah terpencil yang masih sulit untuk mengakses layanan kesehatan. 
Data yang diperoleh peneliti di Puskesmas Belawan selama tiga tahun terakhir menunjukkan data kunjungan pasien rawat jalan meningkat, yaitu pada tahun 2015 sebanyak 27.982 jiwa, tahun 2016 sebanyak 58.215 jiwa dan tahun 2017 sebanyak 63.343. Peningkatan kunjungan pasien dikarenakan pasien yang berobat ke puskesmas mendapat pengobatan gratis dengan menggunakan BPJS, rumah pasien lebih dekat dengan Puskesmas Belawan sehingga memudahkan untuk berobat, walaupun terjadi peningkatan pasien yang berobat di Puskesmas Belawan, akan tetapi masih ditemukan permasalahan di Puskesmas Belawan.

Berdasarkan survei awal yang dilakukan peneliti di Puskesmas Belawan, hasil wawancara dari 12 pasien rawat jalan terhadap pelayanan petugas kesehatan terdapat 4 pasien rawat jalan yang menyatakan puas, Sedangkan 8 pasien rawat jalan menyatakan tidak puas. pasien yang menyatakan puas terhadap pelayanan bukti fisik yaitu obat selalu tersedia di puskesmas, petugas kesehatan selalu berpenampilan rapi, ruang tunggu dan tempat parkir memadai. Sedangkan pasien yang tidak puas dikarenakan kurangnya pelayanan kehandalan yaitu lamanya waktu tunggu pemeriksaan. Selain itu, pasien juga kurang puas terhadap pelayanan ketanggapan yaitu petugas kesehatan yang tidak singgap dalam menanggapi keluhan masalah kesehatan pasien dan juga Pasien tidak puas terhadap pelayanan jaminan yaitu petugas kesehatan yang kurang ramah dalam melayani pasien.

Pelayanan petugas kesehatan yang kurang maksimal dalam memberikan pelayanan menjadi alasan pasien tidak puas terhadap pelayanan di Puskesmas Belawan seperti petugas yang kurang ramah dalam melayani pasien, lamanya waktu tunggu pendaftaran dan pemeriksaan. Serta Kurangnya kepedulian petugas kesehatan terhadap keluhan masalah kesehatan menjadi masalah pasien tidak puas. Tujuan Penelitian ini adalah untuk mengetahui hubungan kualitas pelayanan dengan kepuasan pasien rawat jalan di Puskesmas Belawan.

\section{METODE}

Penelitian ini menggunakan metode penelitian survey analitik dengan rancangan cross sectional yang merupakan suatu study yang mempelajari hubungan antara faktor penyebab yaitu variabel Kualitas Pelayanan, dengan faktor akibat yaitu Kepuasan Pasien (Notoatmojo, 2013). Lokasi Penelitian ini dilakukan di Puskesmas Belawan. Penelitian ini dilaksanakan dari bulan Januari-Februari 2019. Populasi dalam penelitian ini adalah seluruh pasien rawat jalan yang terdapat di wilayah kerja Puskesmas Belawan tahun 2017 yaitu sebanyak 4.642 pasien rawat jalan dengan menggunakan rumus slovin diperoleh sampel sebanyak 98 responden. Teknik pengambilan sampel dalam penelitian ini menggunakan teknik Purposive Sampling (Arikunto, 2014). Data yang dikumpulkan terdiri dari data primer dan data sekunder. Data primer pada penelitian ini diperoleh dari hasil wawancara 98 orang pasien rawat jalan dan kuesioner pada penelitian. Data sekunder berupa jumlah pasien rawat jalan yang diperoleh peneliti dari rekam medis Puskesmas Belawan. Analisis penelitian ini terdiri dari univariat dan bivariat diolah menggunakan uji 
Jurnal Kesehatan Masyarakat \& Gizi, e-ISSN: 2655-0849

Vol. 2 No.1 Edisi Mei-Oktober 2019

https://ejournal.medistra.ac.id/index.php/JKG

Received: 05 Oktober 2019 :: Accepted: 14 Oktober 2019 :: Published: 31 Oktober 2019

chisquare dengan taraf signifikan sebesar $95 \%$ (a) atau derajat kepercayaan 0,05\%. (Notoadmojo, 2013).

3. HASIL PENELITIAN

Analisis Univariat

Tabel 1 Distribusi Frekuensi Karakteristik Pasien Rawat Jalan

\begin{tabular}{lrc}
\hline Karakteristik & $\mathbf{n}$ & $\mathbf{\%}$ \\
Umur & 12 & 12,2 \\
$17-30$ tahun & 29 & 29,6 \\
$31-44$ tahun & 35 & 35,7 \\
$45-58$ tahun & 16 & 16,3 \\
$59-72$ tahun & 6 & 6,1 \\
$73-86$ tahun & & \\
\hline Jenis Kelamin & 25 & 25,5 \\
Laki-laki & 73 & 74,5 \\
Perempuan & 51 & \\
Lama Berkunjung & 57 & 52,0 \\
$<5 x$ & & 48,0 \\
$>5 x$ & 30 & 30,6 \\
\hline Pendidikan & 22 & 22,4 \\
SD & 42 & 42,9 \\
SMP & 2 & 2,0 \\
SMA & 2 & 2,0 \\
Sarjana & & \\
Akademi & 70 & 70,4 \\
\hline Pekerjaan & 1 & 1,0 \\
Tidak ada & 1 & 11,2 \\
PNS & 5 & 5,1 \\
Wiraswata & 5 & 5,1 \\
Pegawai Swasta & 6 & 6,1 \\
Nelayan & & \\
Pensiunan & & \\
\hline
\end{tabular}

Berdasarkan tabel 1 dapat disimpulkan bahwa mayoritas responden berumur 45-58 tahun yakni sebanyak 35 orang $(35,7 \%)$ dan minioritas responden berumur 73-86 tahun yakni sebanyak 6 orang $(6,1 \%)$. Berdasarkan tabel 1 mayoritas responden berjenis perempuan yakni sebanyak 73 orang $(74,5 \%)$ dan minioritas responden berjenis laki-laki yakni sebanyak 25 orang (25,5\%). Berdasarkan tabel 1 menunjukkan mayoritas lama berkunjung $<5 x$ yakni sebanyak 51 orang $(52,0 \%)$ dan minioritas lama berkunjung $>$ $5 x$ yakni sebanyak 47 orang $(48,0 \%)$. Berdasarkan tabel 1 mayoritas pendidikan responden SMA yakni sebanyak 42 orang $(42,9 \%)$ dan minioritas pendidikan sarjana dan akademi masing masing-masing yakni sebanyak 2 orang $(2 \%)$. Berdasarkan tabel 1 mayoritas pekerjaan tidak ada (IRT) yakni sebanyak 70 orang $(70,4 \%)$ dan minioritas pekerjaan PNS yakni sebanyak 1 orang (1\%). 
Tabel 2. Distribusi Frekuensi Hubungan Kualitas Dengan Kepuasan Pasien Rawat Jalan

\begin{tabular}{|c|c|c|}
\hline Variabel & $\mathbf{n}$ & $\%$ \\
\hline \multicolumn{3}{|l|}{ Kehandalan } \\
\hline Tidak Baik & 61 & 62,2 \\
\hline Baik & 37 & 37,8 \\
\hline \multicolumn{3}{|l|}{ Daya Tanggap } \\
\hline Tidak Baik & 63 & 64,3 \\
\hline Baik & 35 & 35,7 \\
\hline \multicolumn{3}{|l|}{ Jaminan } \\
\hline Tidak Baik & 61 & 62,2 \\
\hline Baik & 37 & 37,8 \\
\hline \multicolumn{3}{|l|}{ Empati } \\
\hline Tidak Baik & 51 & 52,0 \\
\hline Baik & 47 & 48,0 \\
\hline \multicolumn{3}{|l|}{ Bukti Fisik } \\
\hline Tidak Baik & 20 & 20,4 \\
\hline Baik & 78 & 79,6 \\
\hline \multicolumn{3}{|l|}{ Kepuasan Pasien } \\
\hline Tidak Puas & 50 & 51,0 \\
\hline Puas & 48 & 49,0 \\
\hline
\end{tabular}

Berdasarkan Tabel 2 kehandalan mayoritas responden menilai petugas kesehatan adalah buruk yaitu sebanyak 61 orang $(62,2 \%)$ dan minioritas responden menilai petugas kesehatan adalah baik sebanyak 37 orang $(37,8 \%)$. Berdasarkan daya tanggap, mayoritas responden menilai petugas kesehatan adalah buruk yaitu 63 orang $(64,3 \%)$ dan minioritas responden menilai petugas kesehatan adalah baik sebanyak 35 orang $(35,7 \%)$. Berdasarkan jaminan, mayoritas responden menilai petugas kesehatan adalah buruk yaitu 61 orang $(62,2 \%)$ dan minioritas responden menilai petugas kesehatan adalah baik sebanyak 37 orang $(37,8 \%)$. Berdasarkan empati, mayoritas responden menilai petugas kesehatan adalah buruk yaitu 51 orang $(52,0 \%)$ dan minioritas responden menilai petugas kesehatan adalah baik sebanyak 47 orang $(48,0 \%)$.
Berdasarkan bukti fisik, mayoritas responden menilai petugas kesehatan adalah baik yaitu 78 orang $(79,6 \%)$ dan minioritas responden menilai petugas kesehatan adalah buruk sebanyak 20 orang $(20,4 \%)$. Berdasarkan kepuasan pasien, mayoritas menyatakan tidak puas yaitu sebanyak 50 orang $(51,0 \%)$, sedangkan minioritas yaitu sebanyak 48 orang $(49,0 \%)$ menyatakan tidak puas.

$\begin{array}{llr}\begin{array}{l}\text { Hubungan } \\ \text { Pelayanan } \\ \text { Pasien }\end{array} & \begin{array}{c}\text { Dimensi } \\ \text { Dengan }\end{array} & \begin{array}{r}\text { Kualitas } \\ \text { Kepuasan }\end{array} \\ & & \end{array}$

Hubungan kualitas pelayanan dengan kepuasan pasien ditunjukkan pada tabel 3 sebagai berikut : 
Tabel 3 Hubungan Kualitas Pelayanan Dengan Kepuasan Pasien Rawat Jalan

\begin{tabular}{|c|c|c|c|c|c|c|c|}
\hline \multirow[t]{3}{*}{ Variabel } & \multicolumn{6}{|c|}{ Kualitas Pelayanan } & \multirow[t]{3}{*}{ p value } \\
\hline & \multicolumn{6}{|c|}{ Puas Tidak Puas $\quad$ Total } & \\
\hline & $\mathbf{N}$ & $\%$ & $\mathbf{n}$ & $\%$ & $\mathbf{n}$ & $\%$ & \\
\hline rehandalan & & & & & & & \\
\hline Tidak Baik & 25 & 41,0 & 36 & 59.0 & 61 & 100,0 & 0,042 \\
\hline Baik & 23 & 62,2 & 14 & 37,8 & 37 & 100,0 & \\
\hline
\end{tabular}

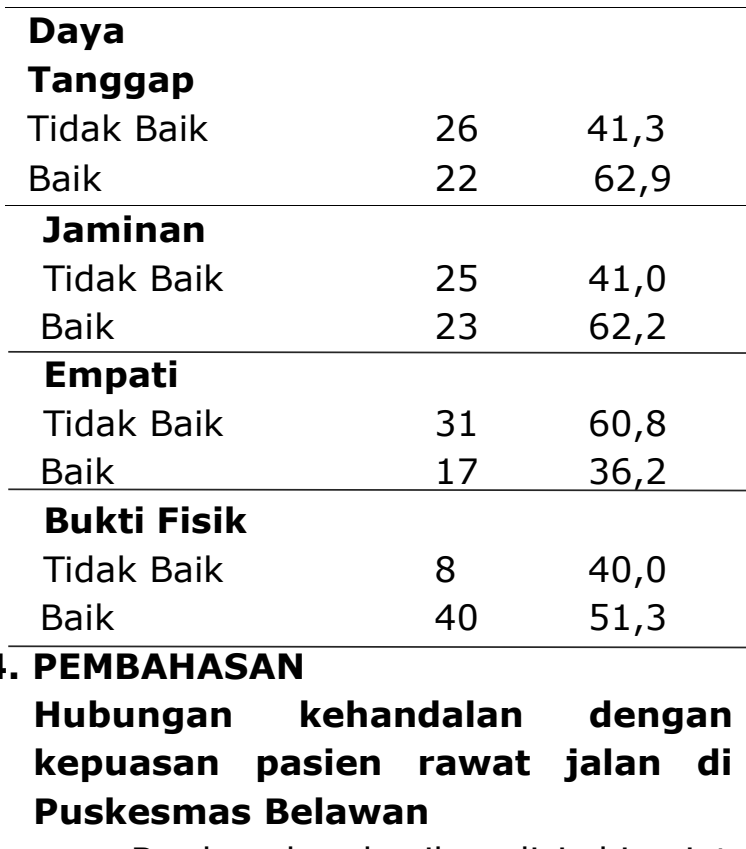

Berdasarkan hasil analisis bivariat dengan menggunakan uji chi-square diperoleh nilai $\mathrm{p}$ value $=0,042$ ( $\mathrm{p}$ value $<0,05)$ artinya Ho ditolak, ini menunjukkan bahwa ada hubungan yang signifikan antara kehandalan dengan kepuasan pasien rawat jalan di Puskesmas Belawan Tahun 2019.

Hasil penelitian ini sejalan dengan penelitian yang dilakukan oleh Wiranto, dkk (2013), p value $(0,001)<$ 0,05 . Hal ini menunjukkan ada hubungan antara ketepatan waktu dengan kepuasan pasien rawat inap di RSUD Lanto Dg. Pasewang Jeneponto. Hasil penelitian ini juga sejalan dengan penelitian yang dilakukan oleh Herman, dkk (2014), $p$ value 0,004 < 0,005. Hal ini menunjukkan ada hubungan antara ketepatan waktu dengan kepuasan pasien di Puskesmas Lembasada Kabupaten Donggala. Penelitian ini didukung oleh teori, Kehandalan (reability) yaitu kemampuan penyedia

$\begin{array}{lllll}37 & 58,7 & 39 & 100,0 & 0,041\end{array}$

$13 \quad 37,1 \quad 59 \quad 100,0$

\begin{tabular}{lllll}
36 & 59.0 & 61 & 100,0 & 0,042 \\
14 & 37,8 & 37 & 100,0 & \\
\hline
\end{tabular}

$\begin{array}{lllll}20 & 39,2 & 51 & 100,0 & 0,015 \\ 30 & 63,8 & 47 & 100,0 & \end{array}$

$12 \quad 60,0 \quad 20 \quad 100,0 \quad 0,368$

$38 \quad 48,7 \quad 37 \quad 100,0$

layanan memberikan pelayanan yang tepat sesuai dengan harapan pasien. Penilaian kehandalan dilihat dari ketetapatan waktu pendaftaran sampai pemeriksaan (Herlambang, 2014).

Berdasarkan observasi dan wawancara menunjukkan bahwa responden kurang puas akan petugas kesehatan yang tidak disiplin kerja, dan prosedur penerimaan pasien tidak dilayani cepat. Artinya, kehandalan perlu ditingkatkan melalui Kepala Puskesmas Belawan agar petugas kesehatan memberikan pelayanan kesehatan secara cepat dan akurat. Dalam hal ini membutuhkan dukungan dari Kepala Puskesmas Belawan untuk memberikan reward agar petugas kesehatan memberikan pelayanan yang cepat dan akurat.

Hubungan daya tanggap dengan kepuasan pasien rawat jalan di Puskesmas Belawan

Berdasarkan hasil analisis bivariat dengan menggunakan uji chi-square diperoleh nilai $p$ value $=0,041$ ( $p$ value $<0,05)$ artinya Ho ditolak, ini menunjukkan bahwa ada hubungan 
yang signifikan antara daya tanggap dengan kepuasan pasien rawat jalan di Puskesmas Belawan Tahun 2019.

Hasil penelitian ini sesuai dengan penelitian yang dilakukan oleh Juwita,dkk (2016), pvalue $0.046<0.05$. Hal ini menunjukkan ada hubungan antara daya tanggap dengan kepuasan pasien rawat jalan di Puskesmas Puriala tahun 2016. Hasil penelitian ini sejalan dengan penelitian yang dilakukan oleh Pangerapan, dkk (2018), p value 0,047 $<0,05$. Hal ini menunjukkan ada hubungan antara daya tanggap dengan kepuasan pasien di Poliklinik penyakit dalam RSU GMIM Pancaran Kasih Manado .

Penelitian ini didukung oleh teori, daya tanggap (responsiviness) yaitu kesigapan petugas kesehatan dalam menanggapi keluhan pasien. Penilaian daya tanggap dilihat dari pelayanan yang cepat dan tenaga kesehatan yang sigap membantu pasien (Tribowo, 2013).

Berdasarkan observasi dan wawancara menunjukkan bahwa responden kurang puas akan petugas kesehatan yang kurang cepat dalam memberikan pelayanan kesehatan. Hal ini dapat dilihat dari jawaban responden yang merasa tidak puas terhadap proses pendaftaraan, pemeriksaan dan pengambilan obat dinilai pasien sering menunggu lama. Artinya, daya tanggap perlu ditingkatkan melalui Kepala Puskesmas Belawan agar petugas kesehatan lebih singgap dalam memberikan pelayanan kepada pasien.

\section{Hubungan jaminan dengan kepuasan pasien rawat jalan di Puskesmas Belawan}

Berdasarkan Hasil analisis

bivariat dengan menggunakan uji chisquare diperoleh nilai $\mathrm{p}$ value $=0,042$ ( $p$ value $<0,05$ ) artinya Ho ditolak, ini menunjukkan bahwa ada hubungan yang signifikan antara jaminan dengan kepuasan pasien rawat jalan di Puskesmas Belawan Tahun 2019.

Hasil penelitian ini sejalan dengan penelitian Jusriani, dkk (2016), pvalue $0.048<0.05$. Hal ini menunjukkan ada hubungan antara jaminan dengan kepuasan pasien rawat jalan di Puskesmas Puriala tahun 2016. Hasil penelitian ini tidak sejalan dengan penelitian Siti \& Sudirman (2015), p value $0,051>0,05$. Hal ini menunjukkan tidak ada hubungan antara jaminan dengan kepuasam pasien rawat inap di Rumah Sakit Umum Daerah Ampana Kabupaten Tojo Una-Una.

Penelitian ini didukung oleh teori, jaminan (Assurance) yaitu kemampuan tenaga kesehatan dalam memberikan jaminan dan keamanan sehingga menumbuhkaan kepercayaan pasien terhadap pelayanan yang diberikan tenaga kesehatan (Tribowo, 2013).

Berdasarkan observasi dan wawancara menunjukkan bahwa responden tidak puas terhadap sikap petugas kesehatan yang kurang ramah dalam memberikan pelayanan kesehatan. Artinya, jaminan perlu ditingkatkan melalui Kepala Puskesmas Belawan agar petugas kesehatan lebih ramah dalam memberikan pelayanan kepada pasien yang berobat di Puskesmas Belawan.

\section{Hubungan empati dengan kepuasan pasien rawat jalan di Puskesmas Belawan}

Berdasarkan Hasil analisis bivariat dengan menggunakan uji chisquare diperoleh nilai $\mathrm{p}$ value $=0,015$ ( $p$ value $<0,05$ ) artinya Ho ditolak, ini menunjukkan bahwa ada hubungan yang signifikan antara empati dengan kepuasan pasien rawat jalan di Puskesmas Belawan Tahun 2019.

Hasil Penelitian ini sejalan dengan penelitian (Mernawati \& Zainafree, 2016), $p$ value $0.03<0.05$. Hal ini menunjukkan ada hubungan antara 
empati dengan kepuasan pasien di Puskesmas Lamper Tengah.

Penelitian ini didukung oleh teori, empati (Emphaty) yaitu perhatian yang diberikan puskesmas terhadap pasien dan keluarganya seperti, kemampuan untuk berkomunikasi dan perhatian yang tinggi dari petugas kesehatan (Tribowo, 2013).

Berdasarkan observasi dan wawancara menunjukkan bahwa responden kurang puas terhadap dokter yang memberikan pelayanan yang cukup kepada pasien. Hal ini dapat dilihat dari jawaban responden yang tidak puas terhadap dokter yang hanya memberikan informasi singkat terikat penyakit yang di derita pasien, Padahal pasien mengharapkan dokter memberikan informasi yang lengkap terhadap penyakit yang pasien derita. Artinya, empati perlu ditingkatkan oleh Petugas Kesehatan seperti dokter, perawat dan lain-lain. agar pasien yang berobat di Puskesmas Belawan puas akan pelayanan empati.

\section{Hubungan bukti fisik dengan kepuasan pasien rawat jalan di Puskesmas Belawan}

Berdasarkan hasil analisis bivariat dengan menggunakan uji chi-square diperoleh nilai $\mathrm{p}$ value $=0,368$ ( $\mathrm{p}$ value $>0,05)$ artinya Ho diterima, ini menunjukkan bahwa tidak ada hubungan yang signifikan antara bukti fisik dengan kepuasan pasien rawat jalan di Puskesmas Belawan Tahun 2019.

Hasil penelitian ini sejalan dengan penelitian (Kahar, Palu, \& Raodhah, 2017), pvalue $0.08>0.05$. Hal ini menunjukkan tidak ada hubungan antara bukti fisik dengan kepuasan pasien di RSUD Barru Sulawesi Selatan. Hasil penelitian ini tidak sejalan dengan penelitian Juwita, dkk (2017), p value 0,0001 <0.1. Hal ini menunjukkan ada hubungan bukti fisik dengan kepuasan pasien rawat inap di Rumah Sakit Umum Daerah Tamiang Layang.

Penelitian ini didukung oleh teori, bukti fisik (Tangible) yaitu wujud kenyataan untuk menampilkan terbaik bagi pasien meliputi penampilan dan kelengkapan fisik (Tribowo, 2013).

Berdasarkan observasi dan wawancara menunjukkan bahwa responden puas terhadap pelayanan bukti fisik. Artinya bukti fisik atau Tangible tidak terlalu berpengaruh terhadap pelayanan kesehatan dikarenakan bukti fisik yang ada di Puskesmas Belawan sudah memadai dari segi fasilitas fisik dan sarana perlengkapan Puskesmas Belawan selalu tersedia.

\section{KESIMPULAN}

Kesimpulan dari penelitian ini adalah adanya hubungan kehandalan dengan kepuasan pasien rawat jalan di Puskesmas Belawan tahun 2019 nilai $p$-value $=0,042(p<0,05)$; Adanya hubungan daya tanggap dengan kepuasan pasien rawat jalan di Puskesmas Belawan tahun 2019 nilai $p$-value $=0,041(p<00,05) ; \quad$ Adanya hubungan jaminan dengan kepuasan pasien rawat jalan di Puskesmas Belawan tahun 2019 nilai $p$-value = $0,042$ ( $p<0,05)$; Adanya hubungan empati dengan kepuasan pasien rawat jalan di Puskesmas Belawan tahun 2019 nilai $p$-value $=0,015(p<0,05)$; Tidak adanya hubungan bukti fisik dengan kepuasan pasien rawat jalan di Puskesmas Belawan tahun 2019 nilai $p$-value $=0,368(p>00,05)$.

\section{DAFTAR PUSTAKA}

Arikunto S. (2014). Prosedur Penelitian Suatu Pendekatan Praktik. Jakarta: Rineka Cipta.

Herlambang S. (2018). Manajemen Pelayanan Kesehatan Rumah Sakit. Yogyakarta: Gosyen.

Herman; Sudirman; Nizmayanun N (2014). Hubungan Kualitas Pelayanan Dengan Kepuasan Pasien Rawat Jalan Di Puskesmas 
Lembasada Kabupaten Donggala. Jurnal Kesehatan Masyarakat, Vol 2(5),30-31.

Jusriani, Junaidi L. (2016). Hubungan Mutu Pelayanan Kesehatan Dengan Kepuasan Pasien Rawat Jalan Puskesmas Puriala Kecamatan Puriala Kabupaten Konawe. Jurnal Kesehatan Masyarakat, Vol 1 (1), 9-10.

Juwita, Grace Siama;Marlinae, Lenie; Rahman F. (2017). Hubungan Mutu Pelayanan Dengan Kepuasan Pasien Rawat Inap Di Rumah Sakit Umum Daerah Tamiang Layang. Kesehat Masyarakat, Vol 4 (2), 54-56.

Kahar, Ayu Wulandari;Palu, Basir; Raodhah S. (2017). Pengaruh Persepsi Mutu Pelayanan Kebidanan Terhadap Kepuasan Pasien Rawat Inap di RSUD Barru Sulawesi Selatan Tahun 2017. Public Heal Sci, Vol 9 (2), 124-126. Legatum Prospety Index. (2016). Rangking Kesehatan Luxembourg. https://www.prosperity.com/ (accessed August 20, 2018).

Legatum Prospety Index. (2016). Rangking Kesehatan Singapore. https://www.prospety.com/ (accessed August 20, 2018).

Mernawati, Delfi; Zainafree I. (2016). Analisis Faktor-Faktor Yang Berhubungan Dengan Tingkat Kepuasan Pasien Rawat Jalan Di Puskesmas Lamper Tengah Kecamatan Semarang Selatan Kota Semarang. Jurnal Kesehatan Masyarakat, Vol 1(1), 49-50.

Notoadmojo S. (2013). Metologi Penelitian Kesehatan. Jakarta: Rineka Cipta;

Sitti, Nurhaida, Surdirman. (2015). Hubungan Kualitas Pelayanan Dengan Kepuaan Pasien Rawat Inap Di RSUD Ampana Kabupaten Tojo Una-Una. Jurnal Tadulako, Vol 2 (1), 21-22.

Pangerapan, Djeinne Thresye; I palandeng, Et Labora Ora; Rattu AJM. (2018). Hubungan Antra Mutu Pelayanan Dengan Kepuasan Pasien di Poliklinik Penyakit Dalam Rumah Sakit Umum GMIM Pancaran Kasih Manado. Jurnal Kedokteran, Vol 2 (1), 13-4.

Profil Puskesmas Belawan. (2015).

Profil Puskesmas Belawan. (2016).

Profil Puskesmas Belawan. (2017).

Triwibowo C. (2013). Manajemen Pelayanan Keperawatan Di rumah Sakit. Jakarta: CV. Trans Info Media.

Wiranto, Muh, Nurhayanti; I. (2013). Analisis Kepuasan Pada Instalansi Rawat Inap Di Rumah Sakit Umum Daerah Lanto DG. Pasewang Kabupaten Jeneponto. Jurnal Kesehatan Masyarakat, Vol 1 (1), 5-6. 